\title{
Research Article Natural Circulation in the ATUCHA-I PHWR Nuclear Power Plant
}

\author{
O. Mazzantini, J. C. Ferreri, F. D’Auria, and C. P. Camusso
}

Received 9 January 2007; Accepted 17 May 2007

Recommended by Oleg Novoselsky

A systematic study of natural circulation (NC) in a postulated, varying primary mass inventory scenario at residual power fractions has been performed for a nuclear power plant operating in Argentina. It is a pressurized heavy water reactor, cooled and moderated by heavy water. The analysis seems particularly relevant at present, because a second nuclear power plant (NPP), of similar design and nearly $745 \mathrm{MWe}$, is now under finalization. NRC-RELAP5/MOD3.3 was the code used to perform the simulations. Results obtained are presented in the form of natural circulation flow maps. The trends obtained fit in the expected limits for integral test facilities representative of PWRs. In addition, the validity of a simplified analysis to scale single and two-phase core flow has been verified. A set of constants has been obtained, which permits predicting NC core mass flow rate (CMFR) for this NPP. Results are partially validated, for single-phase NC flow, using a documented plant transient, showing reasonable agreement. Also, the effect of pressurizer size on the predicted evolution curve in the NC flow map (NCFM) is discussed.

Copyright (C) 2007 O. Mazzantini et al. This is an open access article distributed under the Creative Commons Attribution License, which permits unrestricted use, distribution, and reproduction in any medium, provided the original work is properly cited.

\section{INTRODUCTION}

The central nuclear Atucha I (CNA-I) is a two-loop, 345MWe, pressurized heavy water reactor (PHWR) nuclear power plant (NPP), operating in Lima, Argentina. The NPP is cooled and moderated by heavy water. The reactor core consists of 253 vertical natural uranium fuel assemblies located in the same number of coolant channels. The coolant channels are surrounded by the moderating heavy water, which is enclosed in the moderator (MOD) tank. For reactivity reasons the moderator is maintained at lower temperature than the reactor coolant. This is accomplished by the MOD system, which extracts the moderating water from the MOD tank, cools it in the MOD coolers and feeds it back to the MOD tank.

During full-load operation, $95 \%$ of the total thermal power is generated in the fuel, and the remaining $5 \%$ in the MOD, because of the neutron moderation. Additionally, approximately $5 \%$ of the thermal power is transferred from the coolant to the MOD through the coolant channels walls, due to the temperature difference between the systems. The heat removed from the MOD is used for preheating the steam generators (SGs) feed water. The reactor coolant system and the MOD system are connected by pressure equalization openings of the moderator tank closure head. Therefore, the pressure differences in the core between the primary coolant and MOD systems are comparatively small, which results in the thin walls for the coolant channels. This allows attaining a very high burn-up. Furthermore, the connection between the reactor coolant system and the MOD system permits the use of common auxiliary systems to maintain the necessary water quality.

The system is structured similarly to a pressurized light water reactor and consists of two identical loops, each comprising a steam generator, a reactor coolant pump, and the interconnecting piping, as well as one common pressurizer. Table 1 shows the main overall data of the plant, while Figure 1 shows a schematic view. The MOD system consists of two identical loops operating in parallel. Each loop comprises MOD cooler, pumps, and the interconnecting lines with valves. The moderator system performs various functions depending on the reactor-operating mode. During normal operation the moderator system maintains the moderator at a lower temperature than that of the reactor coolant. The moderator leaves the top of the moderator tank, flows to the moderator pumps, pumped there through the moderator coolers, and flows back to the bottom of the moderator tank. The heat transferred in the moderator coolers is used to preheat the steam generator feed water. For residual heat removal, the moderator system is switched over to the residual heat removal position by means of the moderator valves. Under this operation mode, the moderator is extracted from the bottom of the moderator tank by the moderator pumps and fed into the loop seal of the reactor coolant loops. During emergency core cooling, the moderator serves as a high-pressure core cooling system. The emergency core 
TABLE 1: CNA-I PHWR NPP overall data.

\begin{tabular}{|c|c|}
\hline \multicolumn{2}{|l|}{ CNA-I overall plant data } \\
\hline Reactor type & PHWR \\
\hline Net power station output & $\sim 345 \mathrm{MWe}$ \\
\hline \multicolumn{2}{|l|}{ Reactor coolant system and moderator system } \\
\hline Total thermal power & $1179 \mathrm{MW}$ \\
\hline Number of coolant channels or fuel assemblies & 253 \\
\hline Active core length & $5300 \mathrm{~mm}$ \\
\hline Shape of fuel assembly & 37-rod cluster \\
\hline \multicolumn{2}{|l|}{ Reactor coolant system and moderator system } \\
\hline Coolant and moderator & $\mathrm{D}_{2} \mathrm{O}$ \\
\hline $\begin{array}{l}\text { Total thermal power transferred to the feed } \\
\text { water/main steam cycle }\end{array}$ & $1186 \mathrm{MW}$ \\
\hline Total thermal power transferred to steam generators & $1076 \mathrm{MW}$ \\
\hline Total thermal power transferred to moderator coolers & $110 \mathrm{MW}$ \\
\hline Number of coolant circuits & 2 \\
\hline Number of moderator circuits & 2 \\
\hline Total coolant circulation flow & $6000 \mathrm{~kg} / \mathrm{s}$ \\
\hline Total moderator circulation flow & $444 \mathrm{~kg} / \mathrm{s}$ \\
\hline Pressure at reactor vessel outlet & 114 bar \\
\hline Coolant temperature at reactor pressure vessel & $300^{\circ} \mathrm{C}$ \\
\hline Average moderator temperature normal/maximum & $170^{\circ} \mathrm{C} / 220^{\circ} \mathrm{C}$ \\
\hline Steam pressure at steam generator outlet & 44 bar \\
\hline Total steam flow & $510 \mathrm{~kg} / \mathrm{s}$ \\
\hline
\end{tabular}

cooling position is similar to that of the residual heat removal. The residual heat removal chain connected to the moderator coolers during emergency core cooling is the same as during residual heat removal.

Natural circulation (NC) plays an important role as a residual heat removal mechanism in the primary system in the nuclear safety evaluation of most small break LOCAs (SBLOCAs). Then, the knowledge of NPP behavior in this regime becomes essential. With this objective in mind, a systematic study of the NC in the CNA-I PHWR NPP was performed. Evaluating how the CNA-I PHWR NPP would behave in relation to the following:

(a) results for experimental installations and PWRs operating in NC residual heat removal situations,

(b) correlations deduced on the basis of governing equations valid in the same conditions would give a good perspective of the CNA-I plant performance. Also important is that the finalization of the construction of a second NPP, of nearly 745 MWe and based on the same design concepts, makes worth the present results as a base for extrapolation.

D'Auria and Frogheri [1] proposed the use of NC flow maps (NCFMs) to assess PWR performance. In the mentioned paper, they summarized several previous studies and presented results that served to characterize $\mathrm{NC}$ as a system phenomenon in PWRs, gave an overview of the NCFM based upon experimental data, and showed the possibility of extending the range of application of NC heat removal to significant power fractions in the current PWR NPP geometrical layouts. These results are relevant to (a). On the other side, there are many relevant studies related to (b). In this context, it will be shown that the analysis of Duffey and Sursock [2] is still appropriate, because of its simple, physically based, theoretical approach and the consideration given to experiments in integral test facilities (ITFs) corresponding to PWRs.

According to the aforementioned objective, a series of calculations were performed that allowed constructing an NCFM for the CNA-I PHWR NPP.

The boundary conditions were constant power delivered to primary water after reactor SCRAM and set to $2 \%-5 \%$, SG feed water supply assured and maintained at nominal (fractional power) conditions, moderator pumps stopped, main pumps coast-down after SCRAM and total primary mass controlled. This set of BCs specifies a hypothetical scenario, useful to attain the previously stated objective.

The simulated transients have been run allowing the system to lose mass inventory with a staircase-like controlled function, by suitable mass draining through a valve 
Reactor coolant system and moderator system

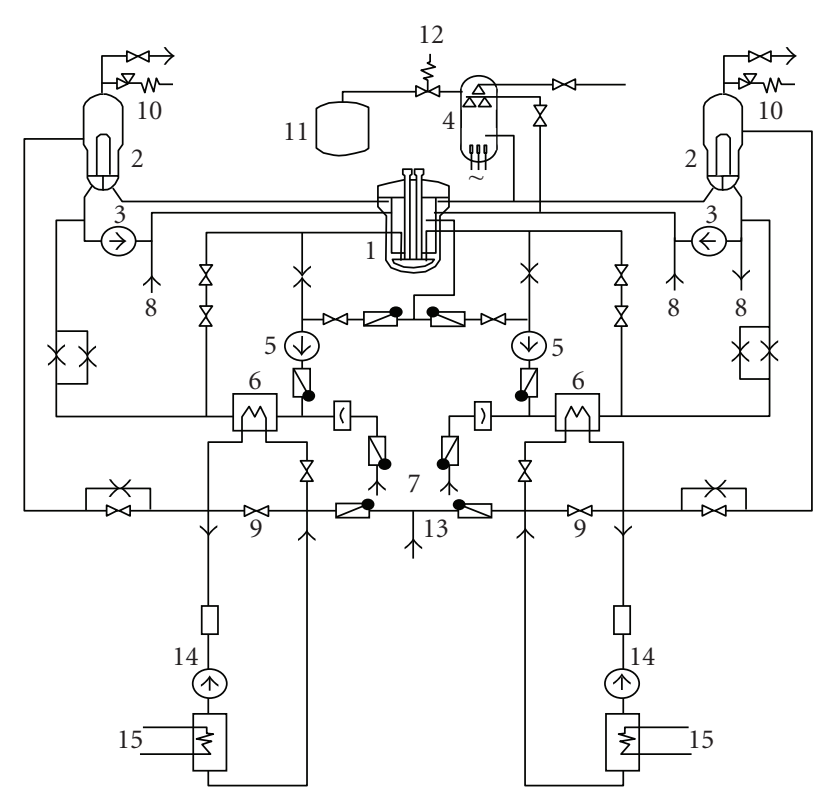

1- Reactor pressure vessel

2- Steam generators

3- Reactor coolant pumps

4- Pressurizer

5- Moderator pumps

6- Moderator coolers

7- Emergency cooling system inlet

8- Pressure and inventory control system

9- Shutdown cooling system (moderator)

10- Secondary side safety valves

11- Pressurizer relief tank

12- Primary side safety valves

13- Secondary inlet light water

14- Residual heat removal system

15- Service cooling water system for plant secured

FIgURE 1: CNA-I PHWR NPP reactor cooling system and MOD system.

connected to one cold leg. This is consistent with the procedures followed in NC in ITFs experimental studies in reduced mass inventory scenarios. The system showed the usual trends in NC heat removal: almost constant singlephase flow, followed by an increase in CMFR with mass inventory decreasing and full two-phase flow in the system. After reaching a maximum, two-phase flow rate began to decrease after subsequent mass loss. The flow stages corresponding to oscillatory two-phase flow and reflux condensation were also found. The analysis of the results obtained and the conclusions reached will be the subject of the following sections. Results using different approaches to plant nodalization have been presented by Ferreri et al. [3]. The contribution of the present paper consists in a detailed discussion of the effect of PRZ size on the NCFM of the installation and a suitable modification of a simplified analysis by Duffey and Sursock [2] that allows approximating the calculated results using a systems thermalhydraulic code and confirming the trends found.

\section{ANALYSIS}

RELAP5/MOD3.3 (US-NRC [4]) was the code used for the analyses. Code runs have been performed at PCs, using precompiled, "as provided" binaries.

\subsection{Nodalization}

The nodalization consists of 983 volumes, 1096 joints, and 1485 heat slabs (11,323 mesh points). The core is subdivided in 15 channels representing 8 hydraulic zones. The active fuel zone is discretized in 20 zones. SGs tubes are also discretised in 20 axial volumes (10 ascending +10 descending) and is the one normally used at the utility for LOCAs simulations. It is schematically shown in Figure 2. In this figure, it may be observed that the secondary side feed water system and the steam system is modeled in a simplified way. The reactor pressure vessel is divided into approximately 500 control volumes taking into account the eight different core coolant channels zones, as shown in Figure 3.

\subsection{Boundary conditions}

The above-described nodalization was not modified to perform this analysis. Safety features, as represented in the RELAP5 nodalization of the plant, have been disabled by appropriate trips.

(i) The SG pressure was kept constant at about 4.0 MPa and the water level was maintained constant with saturated water. In the original design of the plant, the SGs were isolated and the pressure was maintained at the relief valve pressure trip value (approximately 4.2 $\mathrm{MPa}$ ). At present, a new heat removal system was incorporated to the plant to increase its safety. By means of two independent relief valves, one per each SG, the secondary side is depressurized at a $100^{\circ} \mathrm{K} / \mathrm{h}$ rate and two independent emergency secondary feed water systems inject cold water in the SGs.

(ii) The functioning of the MOD system has been described above. In the present simulations, the moderator pumps were stopped and the MOD system was not switched over to the emergency core cooling position. Assuming the conditions mentioned before, the MOD system was almost isolated from the primary system. The communications between the MOD and primary system are the pressure equalization openings of the moderator tank closure heads.

(iii) The volume control system was disconnected.

(iv) No emergency core cooling systems were activated.

(v) A constant decay power was considered to perform the calculations. A parametric study was performed with three different values of decay heat 3\%, 4\%, and $5 \%$ of the nominal reactor power. The decay power was increased by $5 \%$, this part is transferred direct to the moderator system. In this way, the exact decay 


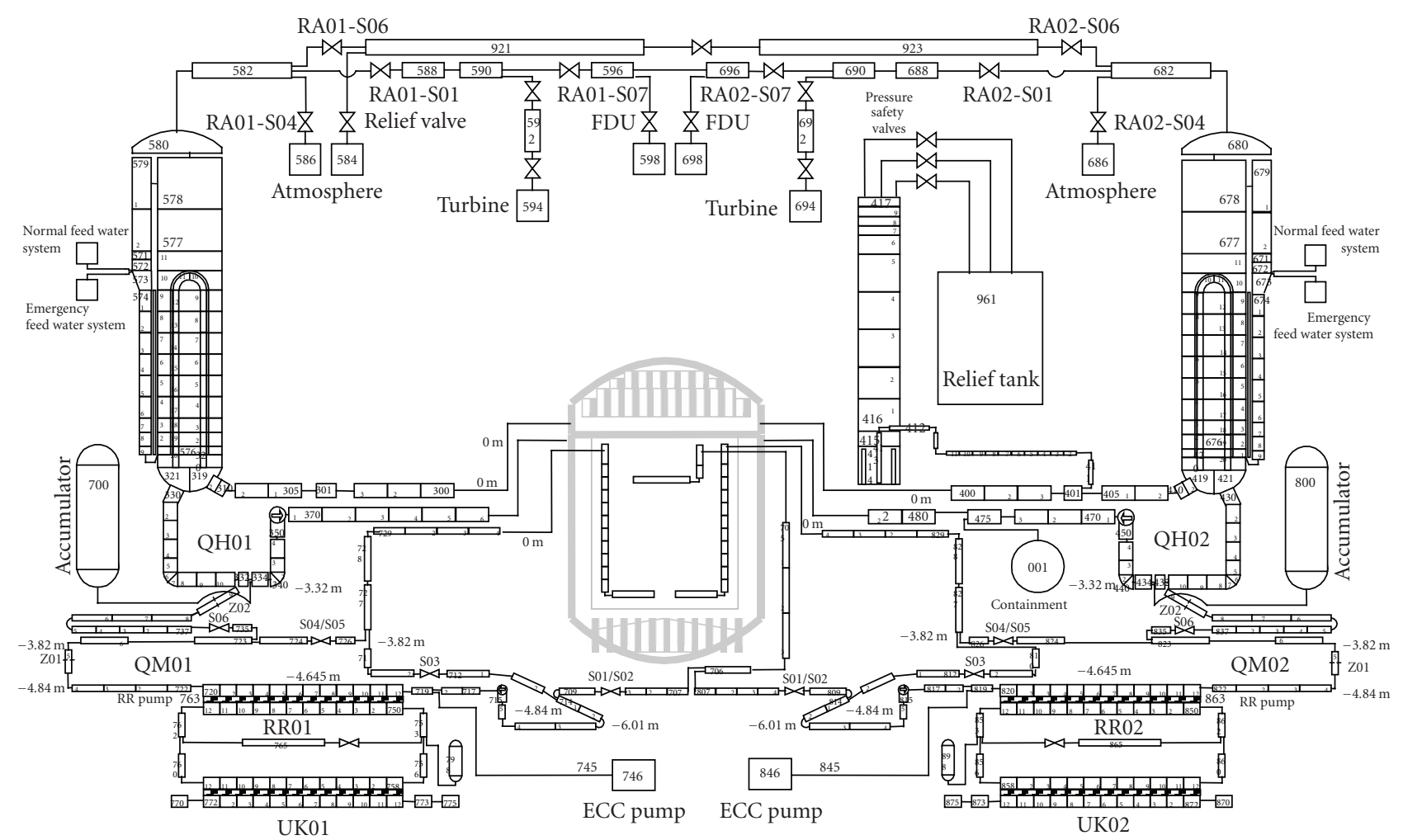

FIGURE 2: CNA-I PHWR NPP Nodalization.

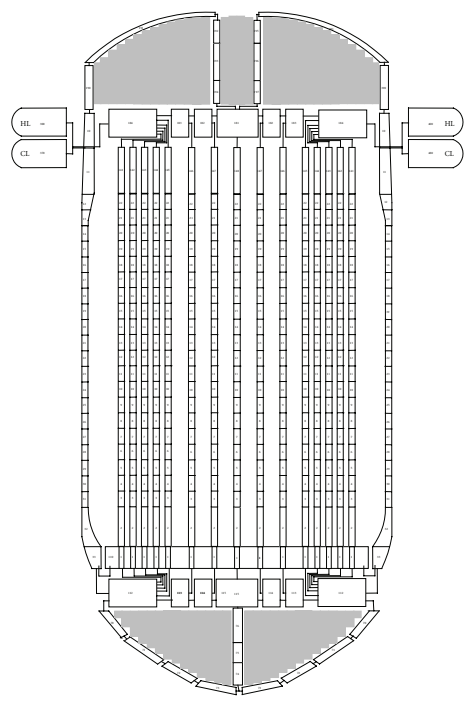

FIgURE 3: CNA-I PHWR NPP core nodalization.

heat for the parametric study is transferred to the primary system. For example, in the case of 5\% decay heat calculation, the decay heat was supposed to be $61.9 \mathrm{Mw}$ (5.25\%). From this power, $58.95 \mathrm{MW}$ $(5 \%)$ are transferred to the primary system, meanwhile $2.9 \mathrm{MW}(0.25 \%)$ are directly transferred to the moder- ator tank. That means that $5 \%$ of the nominal reactor power is transferred to the primary system.

(vi) The reactor SCRAM has been specified by time.

(vii) Pumps have been tripped off by appropriate system signals.

\subsection{Results}

Illustrative results will be presented only for one case. Figure 4 shows one set of results for $P=3 \%$. Figure 5 shows how the power to primary coolant asymptotically tends to the $95 \%$ of the total power. The variation of CMFR corresponding to a very SBLOCA is shown in Figure 6, aimed at showing how the system behaves in a continuously varying mass inventory scenario. The values of CMFR in Figure 6 are similar to the ones in Figure 4 and, in the discussion to follow, the similitude among all the results will become evident. It may be observed that in Figure 4 there is a long time interval at the beginning of the transient, allowing temperature equalization between MOD and primary system. After this period, the heat transferred between both systems may be neglected.

\section{DISCUSSION OF RESULTS}

It is interesting to start the discussion of results with a comparison of the single-phase mass core flowrate with available plant data in a similar scenario. Plant data from an incident will be considered as follows: an unexpected, sudden loss of 


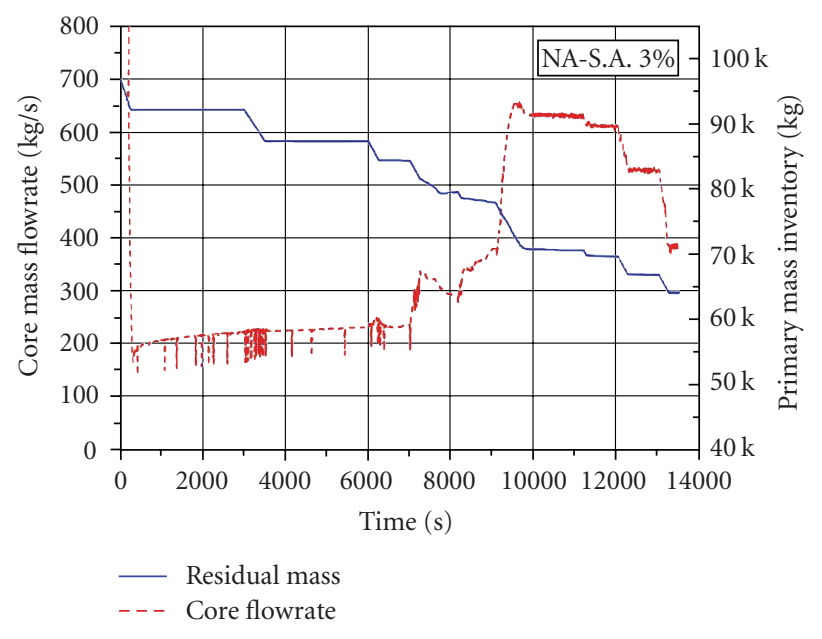

FIgURE 4: CMFR in a reduced, controlled total mass inventory transient, $P=3 \%$. Nodalization is as shown in Figures 2 and 3 .

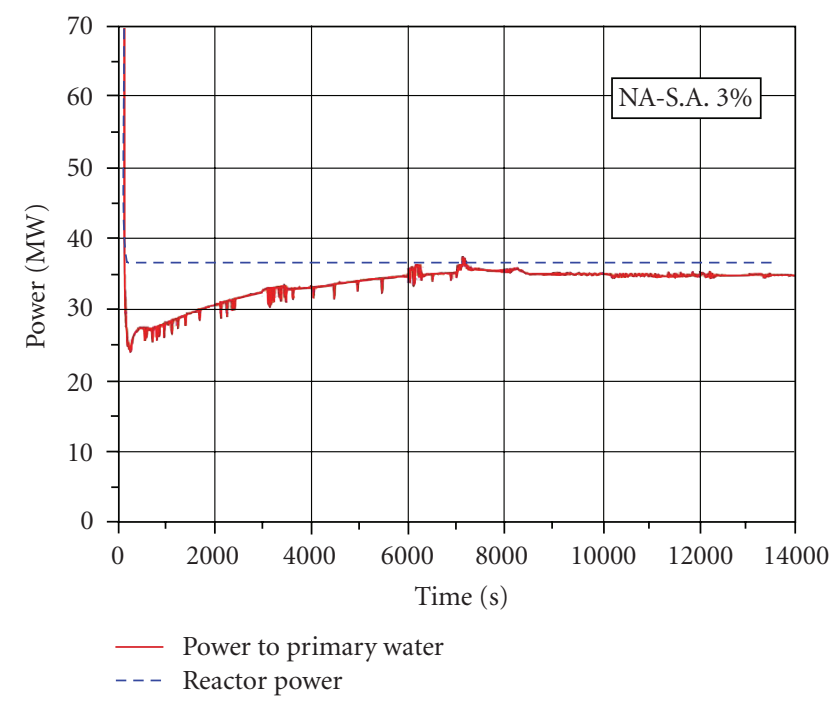

FIGURE 5: Total reactor power and power delivered to primary water.

electricity supply to a system produced the loss of one main coolant pump and the disconnection of one SG feed water pump. This led the plant safety systems to SCRAM the reactor. Additionally, due to loss of pump seal water, the other main coolant pump is also stopped.

The MOD pumps were not tripped. The plant was cooled down by means of NC until the operator switched over the MOD system to residual heat removal position. The plant worked in an NC scenario in single-phase flow during 2100 seconds after the pump coast down. This is similar to the postulated NC scenarios. The real difficulty is that core flowrate is not a reliably measured plant magnitude. Reliable plant measurements in the primary side are: pumps velocity, PRZ level and system pressure, and temperature at different points. In the last case, differences are the most accurate. In

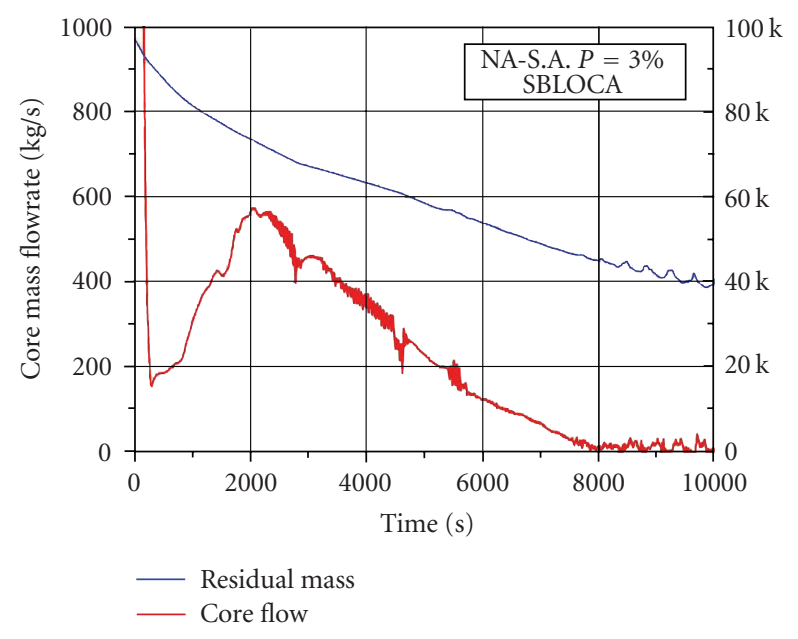

Figure 6: CMFR in a very small SBLOCA, $P=3 \%$.

the secondary side, SGs levels, fluid temperatures, and steam flow rates are also monitored.

The approach to use this data was based on the following: in the continuous set of possible pairs of core flowrate and reactor power, only one pair adjusts the appropriate values of temperature difference between the MOD and the primary and (at the same time) the temperature difference between the primary and the SGs secondary side. It is postulated that reactor power varies according to standard power decay. The reactor SCRAM is produced according to appropriate signals. Then, using: (a) the difference between MOD water cooler input and output temperature, (b) the SGs pressure and downcomer water level as input tables, and (c) letting pumps to trip off with the delay according to the recorded plant data, a transient was simulated starting from nominal conditions. Then, if the system parameters were properly simulated, the correct value of the CMFR would result from all the above-mentioned possible pairs. It must be also considered that an error in the postulated reactor power is attenuated by the 1/third law dependence of mass flowrate versus power delivered to water. Fitting the absolute values of primary and MOD temperatures and pressure to the measured data was somewhat difficult and was done after some trial runs. Figure 7 shows the time evolution of some relevant variables, adopted and simulated.

Primary and MOD temperatures and pressure have been reproduced to a few percent. The same happened with pumps coast-down velocities that obviously, were not entered as input tables. The simulated results are denoted by the prefix R5. Power delivered to primary water was a derived variable and, in the post coast-down time, stabilized at nearly 14 MW. CMFR stabilized around $153 \mathrm{~kg} / \mathrm{s}$ in this period of 2500 seconds of simulated transient. The adequacy of this value will be demonstrated in what follows.

At this point, it is appropriate to discuss the global system behavior and the effects of some set points. To do so, some results will be presented in the context of the analysis of D'Auria and Frogheri [1]. The curves for CMFR, noted 

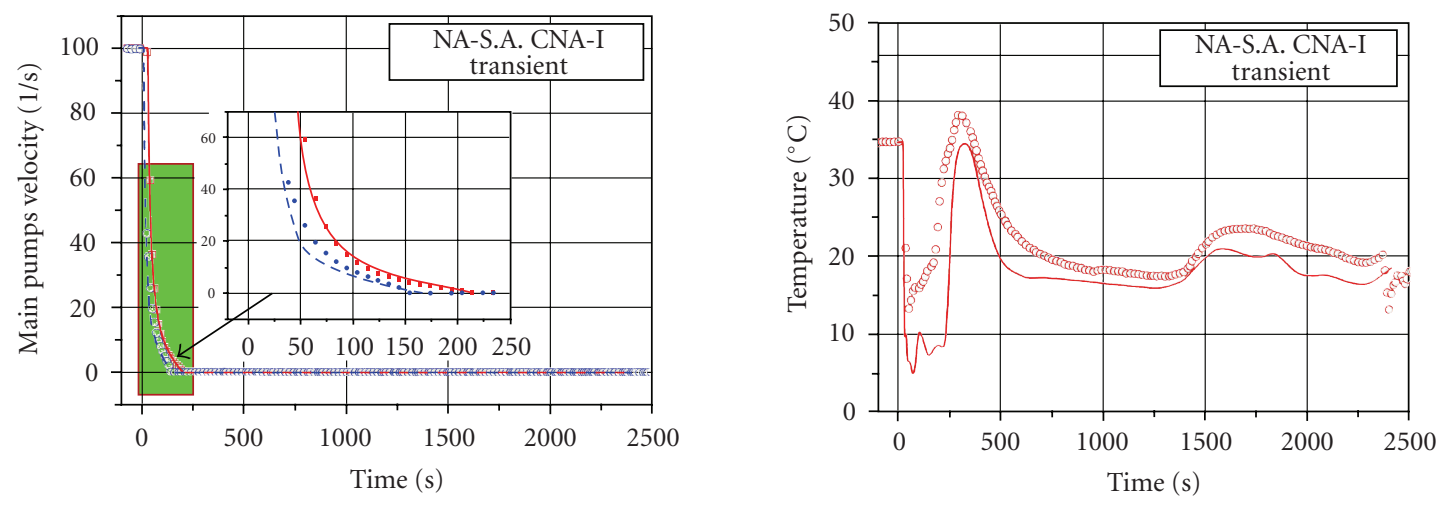

$\begin{array}{ll}\text { CNA-I pump1 } & - \text { R5 pump1 } \\ \circ \text { CNA-I pump2 } & --- \text { R5 pump2 }\end{array}$

- CNA-I primary $\Delta T$ loop 1

- R5 primary $\Delta T$ loop 1
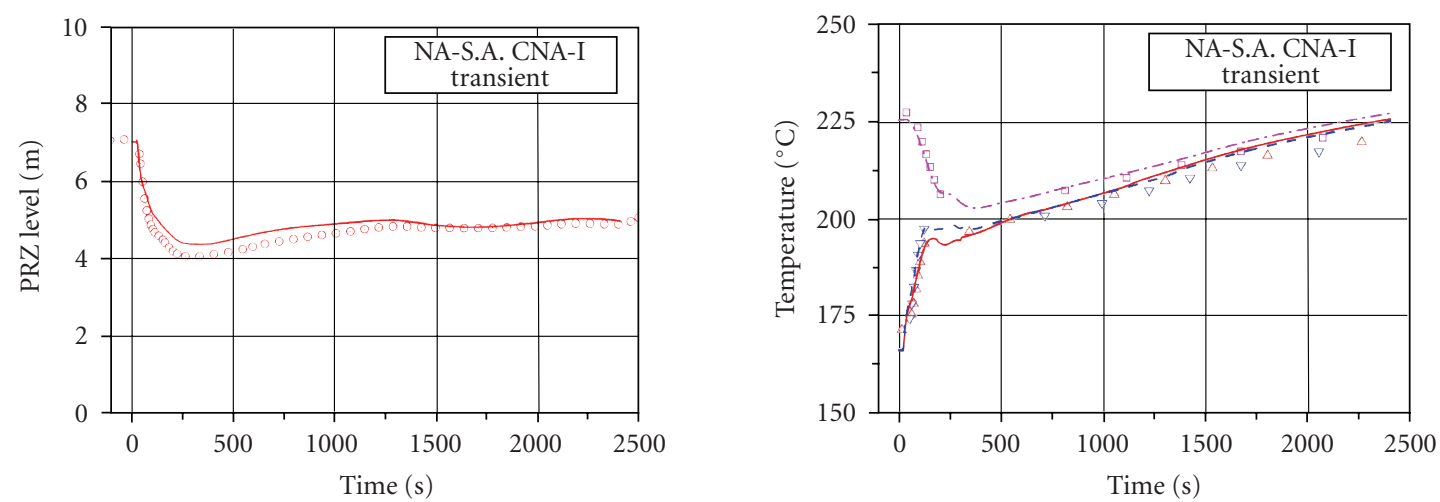

$\odot$ Plant data

- RELAP5
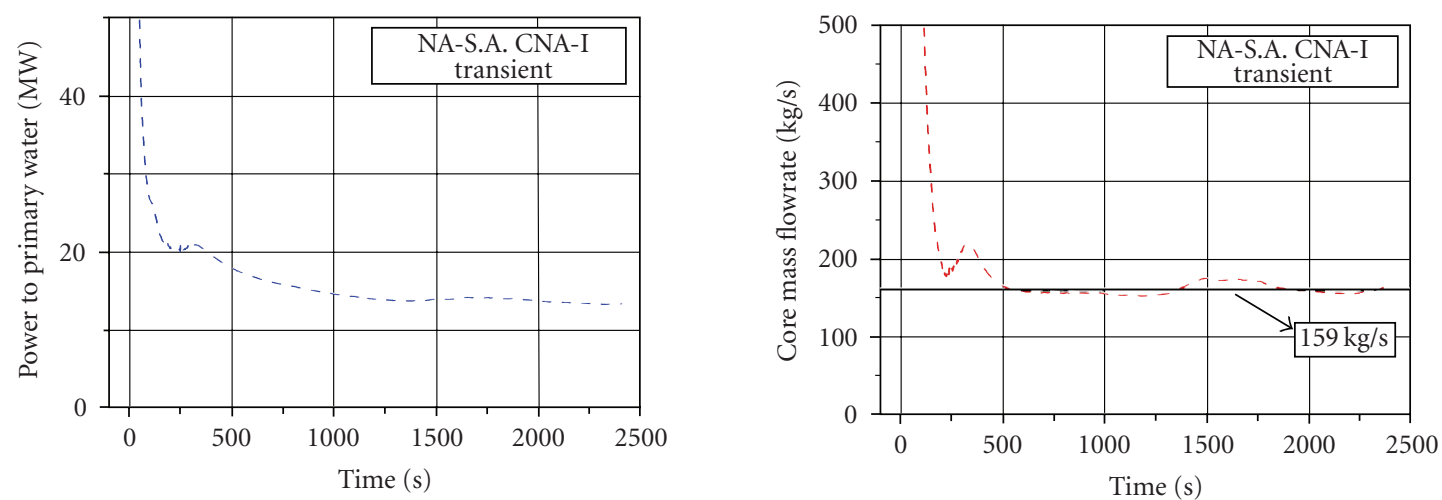

FIGURE 7: Simulation of an NC transient in the CNA-I.

as $W$ in the figures, divided by power to water [kg/MW.s] noted as $P$ in the figures, as a function of the residual mass $(\mathrm{RM})$ in the system divided by the primary volume $\left[\mathrm{kg} / \mathrm{m}^{3}\right]$ are considered. It must be noted that the latter variable is, by definition, an average density. Several considerations must be taken into account in the present analysis. Power to water refers here to the power transmitted to the primary water in the core (it does not include the power to the MOD system). On the other side, system mass refers again to mass in the primary system, without the MOD tank water mass and considering the mass in the PRZ. System volume also includes the PRZ volume. 


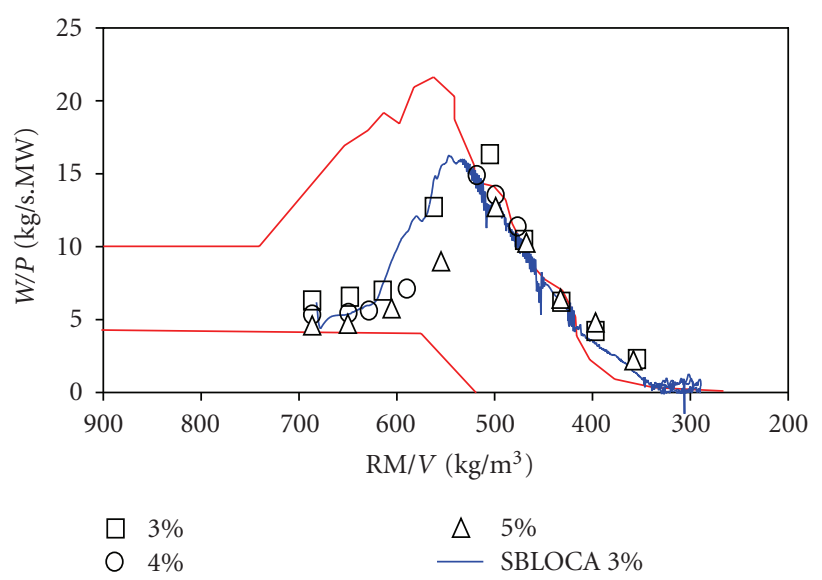

Figure 8: The natural circulation map for CNA-I PHWR NPP.

The results will be presented at first in this way to be consistent with the ones in D'Auria and Frogheri [1]. Figure 8 shows the above-mentioned trends for different power fractions. The curves are consistent with the limits established in the mentioned reference, mainly based on calculated, RMcontrolled transients in ITFs.

The low value initial plateau, when the system is in singlephase, is due to the influence of the MOD system, in this case in combination with the PRZ. It means that in the given restricted geometry/parameter space, the results are consistent with the expected trends for ITFs. Figure 8 also shows the results obtained by simulating some SBLOCA. This behavior is also consistent with the results of D'Auria and Frogheri [1].

It is of interest to discuss now the influence of system geometry on the curve position in the RM/V axis. Figure 9 shows the ratio of the PRZ volume to the primary system volume for different NPPs. They include two, three, and four loops installations of the PWR type and powers ranging between $1000 \mathrm{MWth}$ and $2500 \mathrm{MWth}$. The data corresponding to the CNA-I NPP is explicitly indicated. It can be observed that the ratio varies from 0.23 and 0.17 for the PWRs meanwhile the value for CNAI is 0.42 . It must be pointed out that in the case of the CNAI the primary volume does not include the moderator system. This is the reason for the high value observed, because the PRZ must also compensate the variation of the water inventory in both the primary and the moderator systems.

Figure 10 shows how considering fictitious values of the PRZ volume substantially modifies the NCFM of a nuclear installation, in this case the CNA-I. All curves correspond to a residual power of $3 \%$ of the nominal one. The right one was obtained using the actual volume of the PRZ, the other was constructed using a fictitious PRZ volume with the same ratio of the PRZ volume to the primary system volume as in a 2 loop PWR, and the last one was constructed with the PRZ volume equal to zero. The transient data is the same, starting each case after PRZ emptying and considering appropriate values of system volume in each case. It can be observed that the second curve fits better than the other with the expected trends for ITFs. It means that if the differences between CNAI

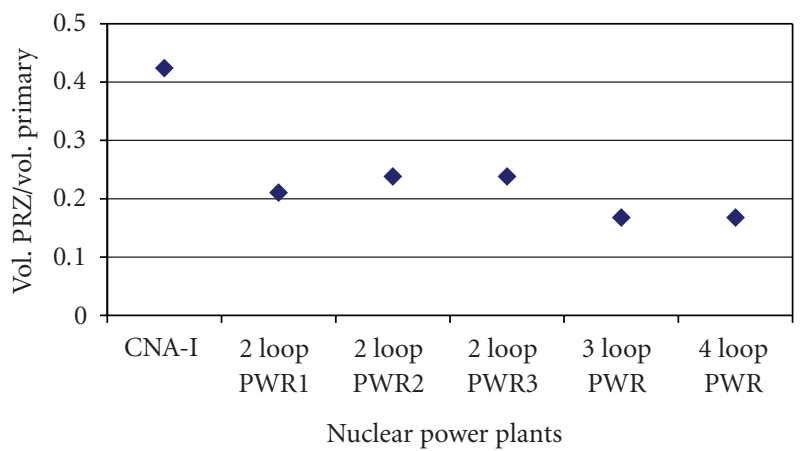

FIgure 9: Comparison of the PRZ geometrical data of the CNA-I with other PWRs.

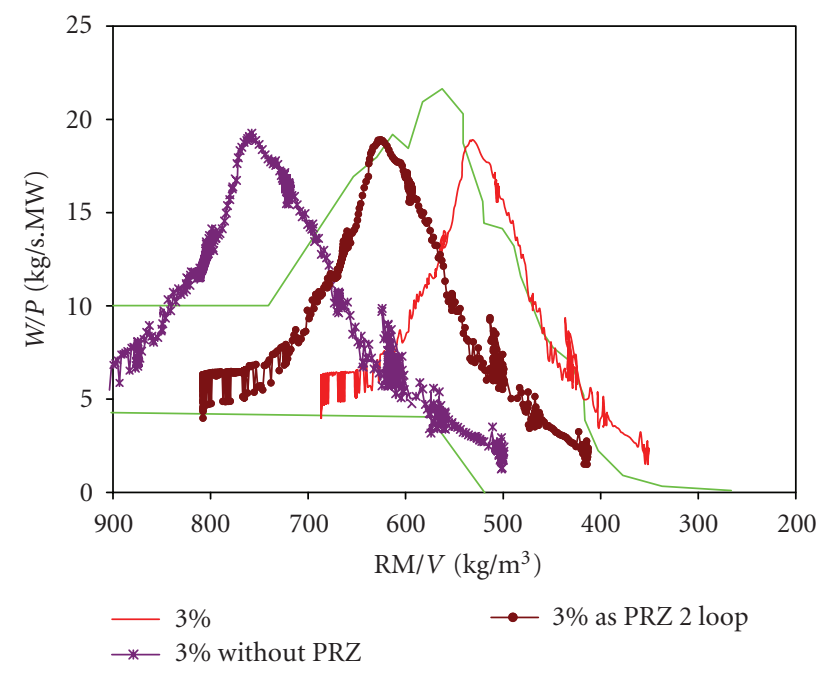

FIgure 10: The effect of considering different PRZ volumes on the CNA-I NCFM.

and a PWR are excluded, the results are more consistent with the NCFM for PWRs. The PRZ does not influence the natural circulation behavior. The PRZ was isolated in some of experiments and the PRZ volume was not included in the primary system volume (like in the case of the ITF reported by Loomis and Soda [5]). Then, attention should be paid to including the PRZ volume in the characterization of reactors that were not represented by the ITFs used to construct the NCFM.

The effect of considering a particular geometry for the PRZ system can be taken into account by a suitable modification of the analysis of Duffey and Sursock [2]. The appendix specifies how this modification must be accomplished. Figure 12 in the Appendix shows that the trends of Figure 10 may be reproduced by applying this simplified theory to the above given nodalization. In this case, different values for PRZ volume have been considered. Consistently, the theoretical curve becomes displaced to the left of the NCFM. 


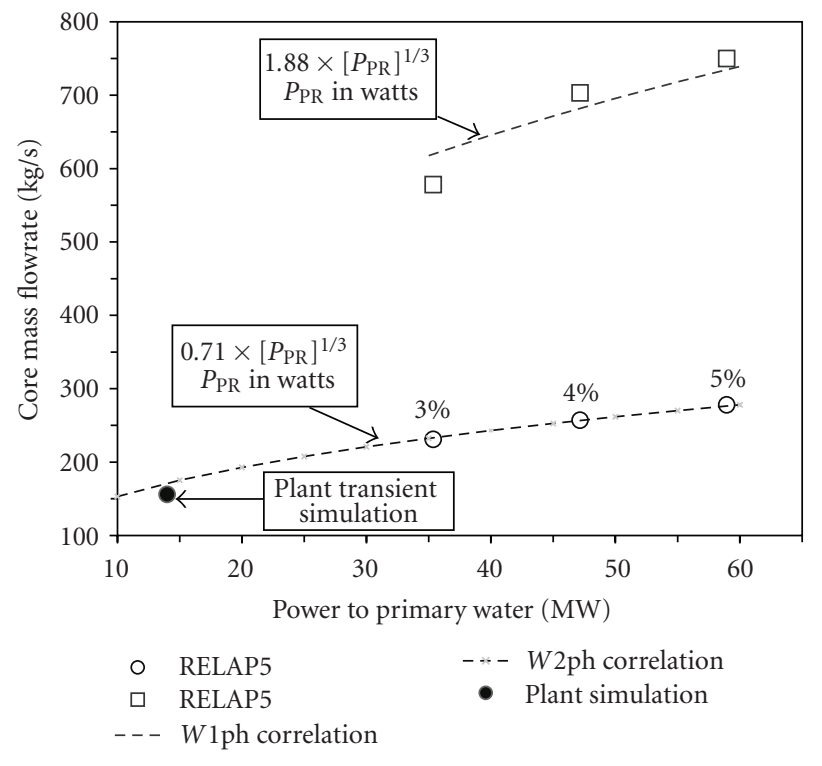

FIgURE 11: One-phase and maximum two-phase flowrate as a function of the power delivered to water (following Duffey and Sursock, [2]).

When the system is "solid," that is, no PRZ is considered, the apparent density (RM/V) of the system becomes equal to the thermodynamic density.

The above-mentioned analysis gives also a background for comparing and discussing results obtained in the simulations. The simplified analysis in this reference allows verifying the one-third-power relationship between loop flow and the power delivered to water. Following Duffey and Sursock [2], it may be written that

$$
\begin{aligned}
W / P^{1 / 3}=F[\text { pressure losses, } \\
\text { thermodynamic conditions and geometry }] .
\end{aligned}
$$

The above expression is valid to evaluate single-phase loop flowrate. The same expression holds for the maximum two-phase loop flowrate, if driving forces are corrected to consider the relative magnitude of volumes with large fractions of vapor void. Assuming that, for a given flow scenario, the right-hand side of this equation may be considered nearly constant and calculating the constants for such cases, the results shown in Figure 11 have been obtained.

A brief discussion of these results follows. Perhaps, one of the most important aspects shown in this figure is the point marked with the label "plan transient simulation," that is the value mentioned at the beginning of this paragraph. It is interesting that this point falls within the $1 /$ third correlation. Constants derived from the correlated points are 0.71 for the average of one-phase flowrate and 1.88 for two-phase maximum flowrate. These are the multiplying constants in the $1 /$ third correlations. It must be noted that the SG secondary conditions are essential to the results shown up to now. A parametric study should consider the variation of this $\mathrm{BC}$, but the specified value (near 4.0 MPa) is consistent with the one recorded in a representative plant transient fitted by the above-mentioned trends.

\section{CONCLUSIONS}

The results presented in the preceding sections are relevant to characterize the behavior of the CNA-I PHWR NPP in NC flows, in a reduced primary mass inventory scenario. The trends known for most ITFs working in similar situations give an envelope to the CNA-I behavior considering appropriate trips of its safety systems. The results have been verified considering a plant transient, which gave results quite similar to the ones obtained by simulation. The results have been correlated using simple expressions in the limited scope of power fractions studied and for a representative set of SGs secondary side BCs. Summarizing, it may be stated that the performed analysis provides new data on the behavior of an existing NPP working in an NC scenario. The data was not previously available. This aspect becomes more important presently, due to the finalization of the CNA-II NPP scheduled for 2010, of nearly 745 MWe and based on the same design concepts.

\section{APPENDIX}

A suitable modification of the original analysis of Duffey and Sursock [2] is introduced in this appendix to better approximate the results of detailed simulations performed using RELAP5, as shown in the main text. Following those authors, the nondimensional mass inventory in the system is defined as

$$
I=\frac{M}{M_{0}},
$$

where $M$ is the mass in the primary system, without considering the PRZ and the MOD system. $M_{0}$ is the value of $M$ before mass extraction. The modification to the original procedure by D and F was verified against RELAP5 detailed calculations as mentioned before.

The modifications consist in:

(a) calculating only one void fraction for the whole hot leg;

(b) determining the inventory corresponding to the zero mass flow condition (the initiation of the reflux condensation) by using the void fraction as obtained from the Zuber-Findlay correlation and, finally;

(c) replacing the function $\Psi$ as specified by Duffey and Sursock to ensure continuity of the flow rate versus mass inventory evolution curves by

$\Psi(I)=\left[1-\left(\frac{1-I_{M}}{I_{M}-I_{W=0}}\right) \frac{V_{2}}{V_{1}}\right]\left(\frac{I-I_{M}}{1-I_{M}}\right)+\left(\frac{1-I_{M}}{I_{M}-I_{W=0}}\right) \frac{V_{2}}{V_{1}}$, 


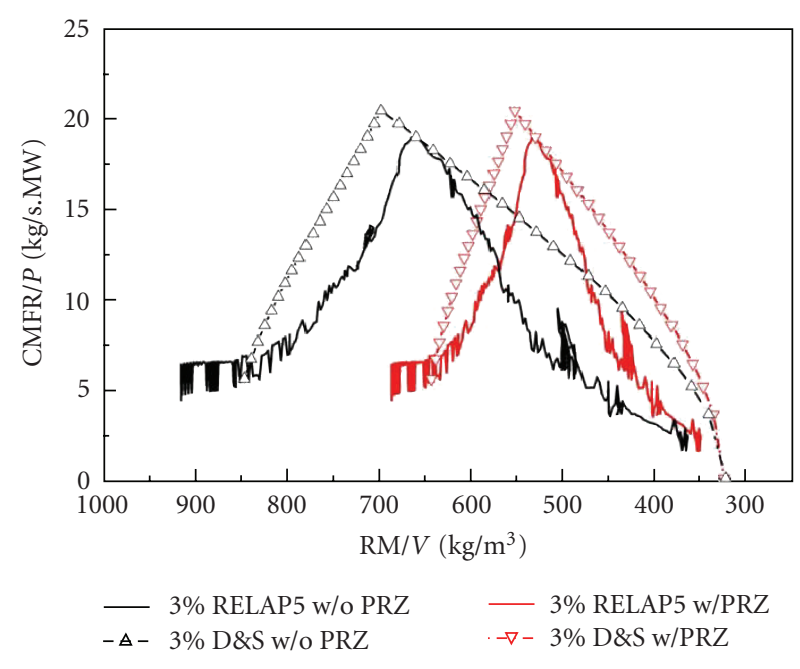

FIGURE 12: The effect of PRZ volume on the NCFM.

TABLE 2: Comparison of results obtained from RELAP5 simulations and the present analysis.

\begin{tabular}{l|ccc}
\hline & This work & $\begin{array}{l}\text { RELAP5 } \\
\text { simulation }\end{array}$ & Error \% \\
\hline$W_{1 \phi}[\mathrm{kg} / \mathrm{s}]$ & 194 & 199 & 2.5 \\
$I_{M}$ & 0.90 & 0.83 & 8.4 \\
$I_{W=0}$ & 0.66 & 0.66 & $\sim 0$ \\
$W_{M}[\mathrm{~kg} / \mathrm{s}]$ & 613 & 595 & 3 \\
\hline
\end{tabular}

where $I_{M}$ is the inventory corresponding to the maximum flow rate, $I_{W=0}$ is the inventory corresponding to zero flow rate, $V_{1}$ is the fraction of system "hot" volume (core, steam generator hot leg, upper plenum, and hot leg) and $V_{2}$ is the cold fraction of system volume (steam generators cold leg downside, pump and downcomer).

This last step ensures 0th-order continuity at the point of maximum mass flow rate and affects the evolution curve from the single-phase flow rate value, leaving it unchanged, up to the two-phase maximum value.

The above-mentioned procedure allows considering the effects of the design peculiarities of the NPP, namely the effects of the PRZ volume. Figure 12 shows how this volume affects the variation of the mass flow rate versus the mass inventory. As may be observed, the effect consists in a shifting of the curve, because of the variation of the calculated average density in the system.

The analysis permits the calculation starting from basic engineering data and may be used as a suitable approximation to the construction of an NCFM. A comparison of the relevant values for this situation is given in Table 2, where $W_{1 \phi}$ is the steady state flow rate and $W_{M}$ is the maximum (two-phase) mass flow rate, showing that the approximation well fits the detailed simulation results.

\section{ABBREVIATIONS}

CMFR: Core mass flow rate

CNA-I: Central nuclear Atucha-I

HL: $\quad$ Hot leg

ITF: Integral test facilities

MOD: Moderator

NC: Natural circulation

NCFM: Natural circulation flow map

NCFR: Natural circulation flow regime

NPP: Nuclear power plant

PHWR: Pressurized heavy water reactor

PRZ: Pressurizer

PWR: Pressurized water reactor

RM: Residual mass in the primary system

SG: $\quad$ Steam generator

\section{REFERENCES}

[1] F. D'Auria and M. Frogheri, "Use of a natural circulation map for assessing PWR performance," Nuclear Engineering and Design, vol. 215, no. 1-2, pp. 111-126, 2002.

[2] R. B. Duffey and J. P. Sursock, "Natural circulation phenomena relevant to small breaks and transients," Nuclear Engineering and Design, vol. 102, no. 2, pp. 115-128, 1985.

[3] J. C. Ferreri, O. Mazzantini, M. A. Ventura, R. D. Rosso, and F. D'Auria, "Natural circulation in the CNA-I PHWR NPPcharacterization based on flow maps," in Proceedings of the 10th International Topical Meeting on Nuclear Reactor Thermal Hydraulics (NURETH-10 '03), Seoul, Korea, October 2003.

[4] United States Nuclear Regulatory Commission, 2001 and 2002 RELAP5/MOD3.3 Code manual, Volumes 1-8, by Information Services Laboratory Inc., Nuclear Safety Analysis Division, NUREG/CR-5535/Rev. 1.

[5] G. G. Loomis and K. Soda, "Results of the Semiscale MOD-2A natural-circulation experiments," Tech. Rep. NUREG/CR-2335; EGG-2200, Idaho National Engineering Laboratory, Idaho Falls, Idaho, USA, 1982.

\section{AUTHOR CONTACT INFORMATION}

O. Mazzantini: Nucleoeléctrica Argentina S.A., UG C.N. Atucha II, Lima 2806, Argentina;

mazzantini@na-sa.com.ar

J. C. Ferreri: Autoridad Regulatoria Nuclear, Av. del Libertador 8250, Buenos Aires 1429, Argentina; jferreri@cae.arn.gov.ar

F. D'Auria: DIMNP, University of Pisa, Via Diotisalvi 2, 56100 Pisa, Italy; d5808@ing.unipi.it

C. P. Camusso: Autoridad Regulatoria Nuclear, Av. del Libertador 8250, Buenos Aires 1429, Argentina; ccamusso@na-sa.com.ar 

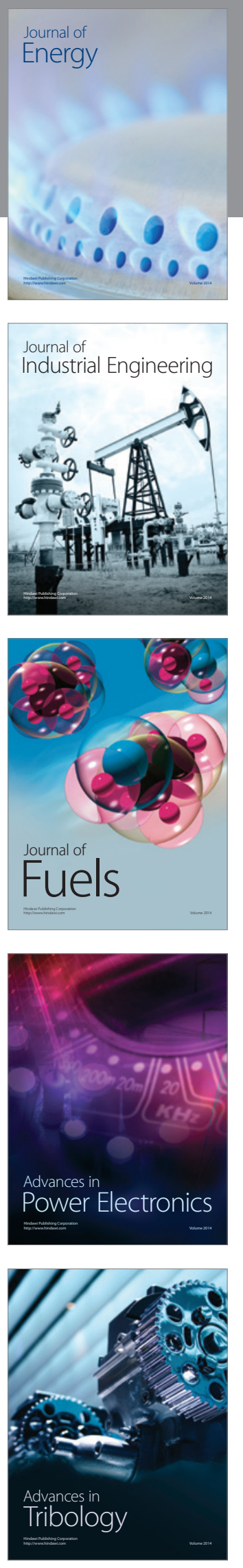
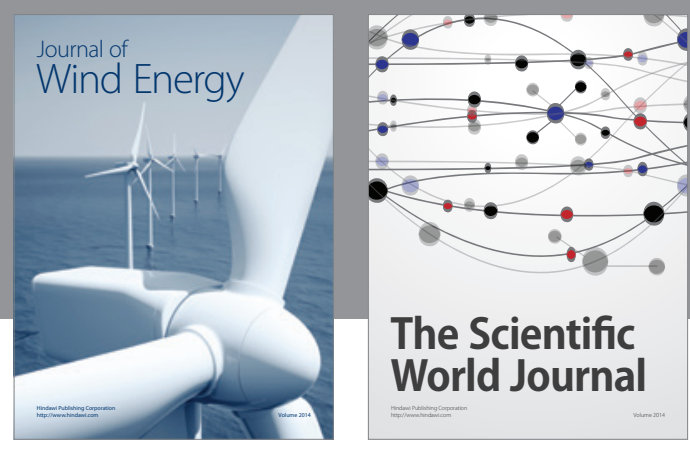

The Scientific World Journal

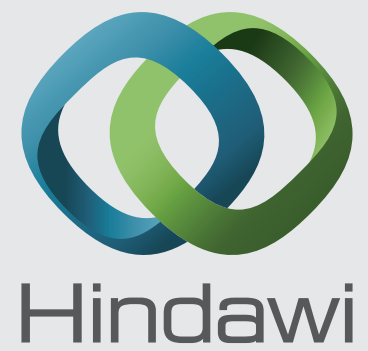

Submit your manuscripts at http://www.hindawi.com
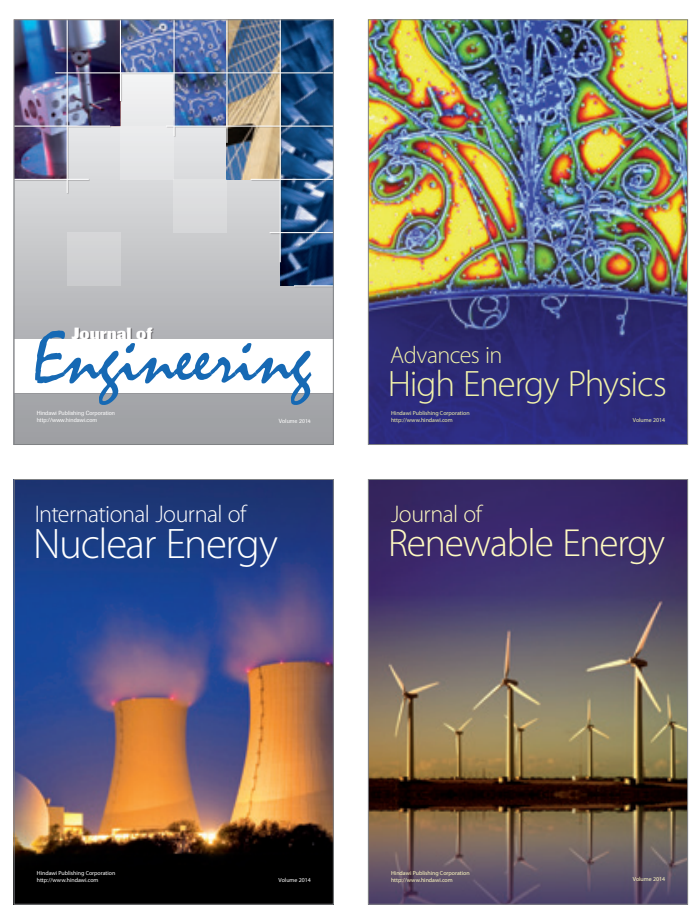

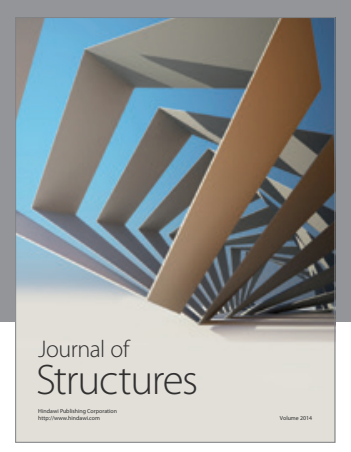

Rotating
Mechinery
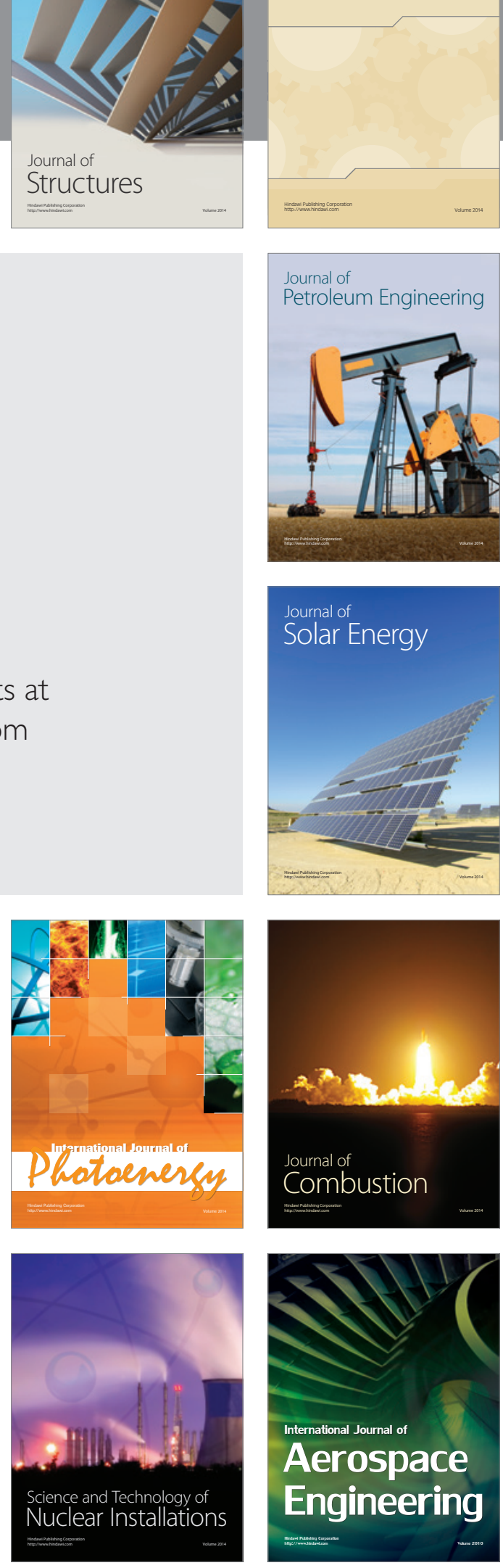